\title{
¿PODEMOS ELEGIR ENTRE PARTICULARISMO Y UNIVERSALISMO?
}

\author{
Bruno Celano \\ Universidad de Palermo, Italia
}

\section{Introducción}

La antítesis entre particularismo y universalismo es uno de los temas más discutidos en la filosofía práctica anglosajona de los últimos años. Pero, ¿de qué tipo de antítesis se trata? Es decir, ¿que género de alternativa constituye la que media entre particularismo y universalismo?

Discutiré este problema tomando como punto de partida las tesis sostenidas por Cristina Redondo. ${ }^{1}$

¿De qué manera ve Redondo la alternativa entre particularismo y universalismo? Creo que su posición puede ser reconstruida del siguiente modo. ${ }^{2}$ En lo que respecta al ámbito jurídico (el campo de las razones jurídicas) la alternativa es, según Redondo, una alternativa entre modelos que, en el plano conceptual (o "analítico-conceptual”) son igualmente válidos, entre los cuales puede (y debe) escogerse, sobre la base de consideraciones ético-políticas (valoraciones sustanciales). Universalismo y particularismo son ambos, por así decir, "modelos ideales" de razonamiento, bajo un perfil conceptual, ambos coherentes y utilizables, en principio, a efectos de ofrecer una reconstrucción (una "reconstrucción racional") de la forma del razonamiento jurídico, o de sectores particulares de éste. Podemos, y debemos, decidir si adecuamos nuestra práctica argumentativa a uno u otro

\footnotetext{
${ }^{1}$ C. Redondo, "Razones y normas", en este volumen (a partir de ahora RyN); id. "Legal Reasons. Between Universalism and Particularism", inédito, 2004 (a partir de ahora LR). ${ }^{2}$ Véase infra, Apéndice I, para una síntesis de los pasos relevantes en RyN y LR.
} 
modelo, si se adopta una o la otra estrategia de decisión. Ambos modelos, entonces, pueden ser adoptados y utilizados como modelos normativos del razonamiento y de la argumentación en el ámbito jurídico: podemos escoger entre sujetar el razonamiento jurídico (o algún sector de él) al modelo universalista o al modelo particularista. Se trata de una elección de tipo normativo sustancial, que dependerá de razones éticas y ético-políticas (razones de política del derecho). En suma: en el plano conceptual, un modelo es tan válido como el otro; se trata de escoger -sobre la base de valores, principios y consideraciones normativas sustanciales-. ${ }^{3}$

En lo que respecta al ámbito de las razones morales (o del razonamiento práctico sin restricciones), ${ }^{4}$ la posición de Redondo no me resulta igualmente clara. ¿Podemos elegir también en este caso entre universalismo y particularismo (esto es, podemos decidir entre adecuar nuestro razonamiento a uno u otro modelo -ambos, por hipótesis, conceptualmente coherentes-), sobre la base de consideraciones normativas o valorativas sustanciales? Redondo no lo afirma explícitamente. Por el contrario, afirma explícitamente que en este caso la alternativa requiere de consideraciones de orden metafísico (el debate actual es "en gran medida, una discusión metafísica"). ${ }^{5}$ Sin embargo, también en este caso los dos modelos son presentados como construcciones analíticas igualmente coherentes; en el plano conceptual -parecería- cada modelo es tan válido como el otro. La alternativa no parece

\footnotetext{
${ }^{3}$ La elección de la que habla Redondo no es -al menos primariamente- de tipo teórico. Se trata en primer lugar de decidir cómo tomar decisiones: siguiendo una estrategia de decision making universalista o particularista. La elección ulterior entre adoptar uno u otro modelo como instrumento de reconstrucción teórica del razonamiento jurídico, o de sectores particulares de él, es parasitaria respecto de la primera opción, de carácter práctico, a favor de una u otra estrategia de decisión.

${ }^{4}$ Utilizaré el adjetivo "moral" como sinónimo de "ético". Ambos hacen referencia a la esfera del razonamiento práctico (de las razones justificatorias de la acción), sin restricciones. No conozco ninguna delimitación plausible (que no tenga carácter estipulativo) de la esfera de las razones "morales" respecto de la esfera de las razones para la acción ordinarias, sin restricciones (esto es, la esfera de la ética, considerada en su conjunto).

${ }^{5}$ RyN, Introducción; cfr. también LR, parte II, Legal Reasons, I c. v.
} 
ser ni conceptual, ni tampoco relativa al plano de la reconstrucción racional (esto es, relativa a la diversa capacidad explicativa de los dos modelos). ${ }^{6}$

No estoy de acuerdo con esto -no del todo, al menos-. En las páginas que siguen, expondré las razones de mi parcial desacuerdo con esta tesis de Redondo. Entre universalismo y particularismo -en una cierta medida, y en un cierto sentido- no podemos escoger. ${ }^{7}$

\section{Razones jurídicas: por qué no tenemos elección}

Comencemos con el derecho, con las razones jurídicas. No existen dudas que aquí, dentro de ciertos límites, sería posible elegir. Los órganos de aplicación y de creación del derecho y, en general, los operadores jurídicos

6 "Explicativa", por supuesto, en el sentido en el que una reconstrucción racional de un ámbito del discurso (o, lo que es lo mismo, de un conjunto de conceptos) pretende tener capacidad explicativa: sacar a la luz la "gramática" del ámbito del discurso objeto de la investigación. (Análogamente al modo en el que una definición informativa se distingue, por un lado, de una definición léxica, cuyos criterios de adecuación son puramente empíricos y, por otro lado, de una definición estipulativa, que como tal es arbitraria). No estoy seguro de que Redondo comparta esta concepción del análisis conceptual, o de la reconstrucción racional de un conjunto de conceptos. (Véanse las alusiones a "un modo diferente de entender el análisis conceptual" en los pasajes transcriptos infra, Apéndice I.) Probablemente mi desacuerdo con Redondo es reconducible, en parte, a esta divergencia de carácter metodológico (posibilidad ésta que la misma Redondo señala: «y es posible que en la presente discusión esté subyacente un desacuerdo también sobre este punto»). Vistas bajo esta luz, las consideraciones que siguen son expresión de una posición crítica en la confrontación de la concepción del análisis conceptual y de la reconstrucción racional que Redondo hace propia y utiliza.

${ }^{7}$ Antes de comenzar, es necesario formular una precisión. Mi visión de la antítesis particularismouniversalismo difiere en un aspecto esencial de la visión que tienen Redondo y otros autores contemporáneos que se han ocupado de este tema. Sobre este aspecto mi posición es heterodoxa. La diferencia es aclarada infra, Apéndice II, donde se indican las razones que, a mi juicio, justifican esta posición. La crítica que dirigiré a Redondo (así como su eficacia) depende también de este diverso modo de comprender la contraposición entre universalismo y particularismo, que se mantendrá en el trasfondo en las siguientes páginas. En particular - y este es el punto esencial- "universalismo", en las paginas que siguen, no comprende aquello que, en el Apéndice II, se denomina "modelo de la ponderación" (posición que por las razones allí especificadas no difiere en modo apreciable, en mi opinión, del particularismo). 
(algunos de ellos, en algunas circunstancias), pueden decidir, sobre la base de consideraciones ético-políticas (por ejemplo, el peso relativo que ha de atribuirse al valor de la certeza, o al carácter previsible de las decisiones judiciales, con respeto a otros valores o, incluso, consideraciones relativas a la conveniencia de dejar librada una cierta esfera de decisión a la competencia de una cierta clase de decisores) sujetar una cierta área, un cierto sector del razonamiento jurídico, a una estrategia de decisión de tipo (al menos en apariencia) universalista. Pueden escoger, por ejemplo, sujetar una cierta esfera de decisión a la decision making basada en reglas («rule-based decision-making», para usar la expresión acuñada por Schauer) o dejar que en esa esfera la decisión asuma características particularistas (por ejemplo, la forma del «rule-sensitive particularism» también delineada por Schauer) ${ }^{8}$

Hay, sin embargo, lugar para un diverso modo de ver las cosas. Si subrayo $s i$ - es verdad que, necesaria (como sostiene, por ejemplo, una versión holística del iusnaturalismo, según la cual existen conexiones holísticas necesarias, sea conceptuales o sustanciales, entre el derecho y los principios y valores éticos) ${ }^{9} \mathrm{o}$ contingentemente (como sostiene el positivismo jurídico incluyente), el derecho incorpora principios y valores éticos (o sea, la existencia y el contenido del derecho dependen de consideraciones éticas sustanciales) y si, en segundo lugar, el razonamiento moral tiene un carácter particularista, entonces, en aquellos casos en los que la existencia y contenido del derecho dependen de consideraciones morales (en otras palabras, cuando y en la medida en la que, para identificar el derecho, sea necesario recurrir a razones morales), el que el razonamiento jurídico asuma un carácter particularista será una necesidad, no una opción. Si estas dos condiciones son satisfechas -y, en tal caso, cuando lo sean-, no tendremos opción entre

\footnotetext{
${ }^{8}$ F. Schauer, Playing by the Rules. A Philosophical Examination of Rule-Based DecisionMaking in Law and in Life, Clarendon Press, Oxford, 1991.

${ }^{9} \mathrm{He}$ delineado las características esenciales de este forma de iusnaturalismo en B. Celano, "Giusnaturalismo, positivismo giuridico e pluralismo etico" (2004), de próxima publicación en Materiali per una storia della cultura giuridica.
} 
el universalismo y el particularismo: el razonamiento jurídico deberá necesariamente ser particularista.

Esta no es, naturalmente, una objeción a Redondo. Al contrario, Redondo reconoce explícitamente que la conjunción del positivismo incluyente y la tesis según la cual el razonamiento moral tiene un carácter particularista lleva a la conclusión de que el razonamiento jurídico es necesariamente, dentro de ciertos límites, de carácter particularista. ${ }^{10}$

No solo eso: esta conclusión depende de dos condiciones (que el derecho incorpore principios y valores éticos, y que el razonamiento moral sea particularista), lo cual, probablemente, Redondo no aceptaría. En lo que respecta a la primera condición, creo que se puede afirmar que ni el positivismo jurídico incluyente ni, a fortiori, el iusnaturalismo holístico que he mencionado, son compartidos por Redondo. De la segunda condición, y del modo en el que Redondo ve la alternativa entre universalismo y particularismo en el ámbito moral, nos ocuparemos en breve. Lo dicho hasta ahora, no obstante, legitima una primera conclusión: limitándonos al campo de las razones jurídicas, que entre el modelo universalista y el modelo particularista haya una alternativa abierta (que los dos modelos sean, en el plano conceptual, igualmente válidos, y que entre ellos se pueda escoger sobre la base de consideraciones normativo-valorativas) es una tesis que depende, no sólo de la reconstrucción de los dos modelos, sino de cuestiones (entre las cuales hay cuestiones conceptuales) acerca de la naturaleza del derecho -en especial, acerca de la relación entre el derecho, por un lado, y los principios o valores éticos, por el otro- y la forma del razonamiento moral. Si se debiera reconocer que el derecho incorpora (necesaria o contingentemente) principios y valores éticos, y que el razonamiento moral tiene carácter particularista, la tesis debería ser abandonada.

Se puede, por lo tanto, presentar una imagen diversa de la que brinda Redondo (según la cual en el ámbito jurídico el razonamiento universalista y el razonamiento particularista son modelos ideales conceptualmente equivalentes,

${ }^{10}$ RyN, II.2; LR, Particularism in the legal domain. 
entre los cuales podemos escoger sobre la base de valores y principios normativos sustanciales). Pero creo que también se puede arriesgar otra.

¿Cuándo es plausible -conceptualmente plausible- la idea de una estrategia de decisión que sea verdaderamente, por completo basada en reglas (es decir, universalista)? Las cláusulas abiertas o estándares en los que figuran conceptos éticos densos son una constante de la cultura jurídica, ${ }^{11}$ la derrotabilidad de las normas jurídicas sobre la base de consideraciones éticas no susceptibles de especificación previa (si no lo es en términos genéricos e indefinidos), constituye también un dato constante. ${ }^{12}$ Esto no excluye, obviamente, que haya sectores particulares del derecho en los cuales estos fenómenos sean, o pueda ocurrir que se tornen, latentes (de hecho, o como consecuencia de expresas disposiciones jurídicas), y que queden en el trasfondo. Pero, en primer lugar, una cosa es que fenómenos de este tipo se encuentren latentes, otra que su posibilidad sea, como tal (bajo cualquier condición hipotetizable), excluida. Y, en segundo lugar, si se contempla al derecho en su conjunto, la hipótesis de que esa posibilidad sea, o resulte, por completo excluida parece bien poco plausible, artificial. Parecería que el recurso a la equidad no es un elemento opcional en el derecho considerado en su conjunto. ${ }^{13}$

\footnotetext{
${ }^{11}$ J. J. Moreso, "In Defense of Inclusive Legal Positivism”, in P. Chiassoni (ed.), The Legal Ought, Giappichelli, Torino 2001; B. Celano, "Come deve essere la disciplina costituzionale dei diritti?”, en S. Pozzolo (a cura di), La legge e i diritti, Giappichelli, Torino, 2002.

${ }^{12}$ Una excepción estaría constituida por un sistema jurídico puramente formalista (sobre el modelo, por ejemplo, de la stipulatio en el derecho romano arcaico; debo esta sugerencia a José Juan Moreso).

${ }^{13}$ Pero, se objetará, todo eso no excluye la posibilidad lógica de un sistema jurídico que esté exento de los fenómenos en cuestión (derrotabilidad sobre bases éticas, recurso a la equidad, etc.). Esto es verdad, y a ello se aferran los defensores del positivismo jurídico incluyente. La corrección del positivismo jurídico incluyente depende, precisamente, de la mera posibilidad lógica de un sistema jurídico que no incorpore principios y valores éticos. Pero creo que eso hace de ella una posición teórica un tanto débil, o de todos modos poco interesante. Su verdad termina dependiendo de la respuesta a un interrogante análogo, por ejemplo, a la pregunta de si un tigre sin bigotes, ni rayas, ni patas..., no pueda no obstante ser "un tigre". La precariedad de la distinción analítico-sintético debería desalentar el planteo de interrogantes de tal género y, con mayor razón, el hacer depender de la respuesta a interrogantes así planteados elecciones teóricas significativas.
} 
Esto sugiere (pero, no obstante, no prueba en forma concluyente) que universalismo y particularismo no son dos modelos que, desde el punto de vista conceptual, se encuentran en el mismo plano. Es cierto que bien puede ocurrir que en cierto sector se adopte un estilo de razonamiento que parezca instanciar el modelo universalista, un estilo de razonamiento que imite el razonamiento universalista. Pero la alternativa entre los dos modelos, y la opción a favor de uno u otro de ellos, es guiada, en última instancia, por un razonamiento que tiene características particularistas: el recurso a una estrategia de decisión (aparentemente) universalista sigue siendo provisorio, y sujeto, en principio, a la posibilidad de ser revocado. En el fondo del razonamiento universalista hay razones particularistas. Es decir, la alternativa entre las dos formas de razonamiento se encuentra gobernada, en última instancia, por el razonamiento particularista -lo cual, como Redondo justamente subraya, equivale al vaciamiento del modelo universalista, y a reconocer la supremacía del modelo particularista-.

El mismo punto puede ser reformulado, utilizando el léxico de Schauer, del siguiente modo ${ }^{14}$ La diferencia entre reglas propiamente dichas (es decir, decision making universalista), por un lado, y rules of thumb (es decir, decision making particularista), por el otro, se configura, en última instancia y no obstante la inicial contraposición cualitativa, como una diferencia de grado. Las reglas (las generalizaciones prescriptivas que llamamos "reglas") son rules of thumb respecto de las cuales las razones que se introducen para rever (es decir, "desatrincherar") la generalización deben ser particularmente fuertes -de otro modo, no les haríamos caso-. Las rules of thumb, por otro lado, son reglas respecto de las cuales dejamos también que ciertas razones relativamente débiles sean suficientes para inducir a rever la generalización. La elección de sujetar una cierta esfera de decisión al

\footnotetext{
${ }^{14} \mathrm{Si}$ esta reformulación respeta o no la posición de Scahuer constituye otra cuestión, de la cual no pretendo ocuparme aquí. No hay duda de que en la teoría de Schauer se encuentran presentes elementos que van en la dirección que se sigue el texto (cfr. Schauer, op. cit., cap. 5). Pero el que las tesis enunciadas en el texto sean efectivamente atribuibles a Schauer depende de consideraciones exegéticas y críticas que aquí resultan irrelevantes.
} 
decision making basado en reglas, entendido como completamente inderrotable, no tendría mucho sentido. El concepto mismo de regla, como cualitativamente distinto de las rules of thumb, parece precario.

En otras palabras, ¿qué tipo de razonamiento es aquel sobre cuya base decidimos en cualquier caso tratar a una generalización prescriptiva como una regla o como una rule of thumb? El que la diferencia sea una cuestión de grado quiere decir, como se acaba de ver, que la decisión depende de la alternativa entre admitir o no que razones poco significativas, de peso escaso, sean suficientes para inducir al desatrincheramiento de una generalización. Ahora, no veo cómo el razonamiento sobre este punto podría ser otro que un razonamiento particularista. Si en un cierto contexto de decisión atrincheramos o desatrincheramos una generalización prescriptiva, y cuándo hemos de hacerlo, dependerá de razones particularistas. La decisión de sujetar al menos un cierto ámbito de decisiones al rule based decision making, y hasta qué punto hacerlo (es decir, cuándo las razones son lo suficientemente fuertes como para inducir el desatrincheramiento de una generalización atrincherada), constituyen la conclusión de un razonamiento particularista. ${ }^{15}$

\footnotetext{
${ }^{15}$ Es cierto que la opción a favor del decision making basado en reglas puede tener sentido, y estar justificada, cuando se trata de atribuir poder y competencia a un conjunto de instituciones encargadas de tomar decisiones, a fin de conferir a los decisiones que operan en este cuadro institucional la competencia para evaluar si la aplicación de la generalización prescriptiva está o no de acuerdo con las razones que subyacen a ella, o si acaso no hay otras razones que superan a estas últimas. Es éste (más que la garantía de certeza o la equidad), según Schauer, el tipo de justificación apropiado para el decision making basado en reglas (las reglas son instrumentos para distribuir el poder; Schauer, op.cit., cap. 7). Pero la cuestión de si vincular las decisiones ajenas respecto de la aplicación de la regla (generalización atrincherada) es completamente diferente de la cuestión de si adoptar, en primera persona (es decir, desde la perspectiva del agente), una estrategia similar de decisión. El primero de estos dos tipos de decisiones es análogo a la decisión de si construir o no una máquina destinada a guiar cierta esfera de actividad (por ejemplo, la decisión de instalar un semáforo en un cruce). La segunda cuestión es -desde la perspectiva de una investigación conceptual, descriptiva, y normativa sobre las razones para la acción- la decisiva (nadie querrá sostener que un semáforo es un decision-maker universalista); y es sobre ella que se vuelcan las consideraciones en el texto. En el mismo sentido, Schauer (op. cit., p. 98, n. 26) concede que «from the perspective of the agent deciding what to do, anything more rule-bound than rule-sensitive particularism is difficult (although I think not impossible) to defend».
} 
¿Pero por qué, si puede preguntarse, la alternativa entre los dos modelos (y la opción a favor de uno u otro) debería necesariamente guiarse, en ultima instancia, por un razonamiento particularista? (¿Por qué en todo caso la decisión entre admitir o no que razones poco significativas, de peso escaso, sean suficientes para inducir al desatrincheramiento de una generalización atrincherada debería necesariamente ser particularista?) Debo confesar que una respuesta positiva a esta pregunta me parece evidente: no llego a ver cómo la cuestión podría plantearse de manera diferente, sin un regreso al infinito. (El razonamiento particularista es, me parece, la posición por default). Los fenómenos que he señalado (cláusulas abiertas y estándares que contienen términos indefinidos, recurso a la equidad, etc.) confirman esta conclusión: el recurso a una estrategia de decisión (aparentemente) universalista permanece como provisorio y sujeto, en principio, a la posibilidad de revocación. Y no sólo esto: esta línea de argumentación es ulteriormente corroborada por una circunstancia que el mismo análisis de Redondo contribuye a sacar a la luz.

Me parece que Redondo no capta un punto de importancia crucial. La elección entre el modelo universalista y el particularista (rectius, a la luz de las consideraciones precedentes, la elección entre un estilo de razonamiento que imita, más o menos fielmente, el razonamiento universalista y un estilo de razonamiento abiertamente particularista), sostiene Redondo, es orientada por consideraciones éticas sustanciales. Esto significa, no obstante, que la elección es gobernada por el razonamiento moral. Si (como sostendré en el punto siguiente) el razonamiento moral es particularista, la elección (en el ámbito jurídico) entre un estilo de decisión universalista y uno particularista será, por cierto, guiada por un razonamiento particularista. ¿Puede evitarse concluir que esto tendrá implicaciones en el plano «analítico conceptual»? No, porque la dependencia del razonamiento universalista de un razonamiento con trasfondo particularista implicaría, como hemos visto, el carácter provisorio y revocable de la (estrategia) de la decisión universalista -sintéticamente, no se trataría de una decisión auténticamente universalista-.

Por lo tanto, el modo en el que se configuren en el plano analítico conceptual los dos modelos de decisiones, en el caso de las razones jurídicas, 
y cuál sea la relación entre ellos, depende de la forma del razonamiento moral. Si en el ámbito jurídico la elección entre los dos modelos depende de razones éticas, cuál sea la relación (conceptual e, inescindiblemente, normativa, como argumentaré en breve) entre los dos modelos dependerá de cuál sea la estructura -universalista o particularista- del razonamiento moral. En suma, nuestra teoría (universalista o particularista) del razonamiento jurídico deberá depender de una teoría del razonamiento moral.

Si la elección entre las dos formas de razonamiento es efectivamente gobernada por razones (morales) particularistas, el razonamiento universalista será necesariamente provisorio y circunscripto, sujeto a la posibilidad de revocación: no se tratará de un razonamiento universalista, sino de una forma de razonamiento que imita el razonamiento universalista (una estrategia de decisión "para-universalista"). Lo cual, por cierto, equivale al vaciamiento del modelo universalista y al reconocimiento de la supremacía (conceptual $e$ inescindiblemente, normativa, como veremos en breve) del modelo particularista. Los dos modelos no están conceptualmente en el mismo nivel.

Estas consideraciones, por lo tanto, sugieren (aunque no demuestran) que, en el ámbito jurídico, entre el modelo universalista y el modelo particularista no tenemos opción. ¿En qué sentido "no tenemos opción"? No pretendo afirmar que no sea empíricamente posible adoptar, con relación a un cierto sector del razonamiento jurídico, el modelo universalista. No pretendo negar el hecho obvio de que en sectores particulares del razonamiento jurídico, en áreas específicas del derecho, predominan estilos de razonamiento fuertemente inclinados hacia el atrincheramiento de las generalizaciones prescriptivas relevantes -estilos de razonamiento que parecen ubicarse en los extremos del modelo universalista (que imitan muy fielmente el razonamiento universalista). Más bien, la idea de que en el ámbito jurídico "no tenemos elección" entre los dos modelos ha de entenderse en el siguiente sentido. La alternativa constituye, efectivamente, una cuestión normativa: estamos por cierto discutiendo acerca de modelos de razonamiento (es decir, formas de razonamiento correcto, o formas de razonamiento tout court: la 
propia noción de razonamiento es una noción normativa). ${ }^{16}$ Pero la cuestión es, en efecto, conceptual. Lo que sugieren las consideraciones efectuadas (esto es, lo que los argumentos ofrecidos probarían si fuesen sólidos) es que el modelo universalista resulta conceptualmente insatisfactorio -es decir, que desde el punto de vista conceptual no es válido en el mismo grado que el modelo particularista-. La alternativa entre razonamiento universalista y particularista es gobernada por razones particularistas. Se trata de una cuestión normativa, en el sentido que constituye una cuestión de racionalidad sustancial, o de razonabilidad. Lo que se encuentra en cuestión no es la mera posibilidad lógica, ni qué sea empíricamente posible. Es lógicamente posible que, con respecto a una cierta esfera de decisión (jurídica), se adopte un modelo universalista, y puede que de hecho eso suceda. Pero la idea de una decision making basada en reglas, en sentido propio, no es razonable. El modelo resulta (si no incoherente) conceptualmente insatisfactorio. Y al mismo tiempo es inescindiblemente, conceptual y normativamente, insatisfactorio. Aquí lo normativo y lo conceptual resultan indistinguibles. La normatividad en cuestión es normatividad epistémica.

\section{Razones morales: por qué no tenemos opción}

Consideremos ahora a las razones morales. ¿Se encuentran los dos modelos en el mismo plano desde el punto de vista conceptual? ¿Se trata de una cuestión de elección? No. El modelo universalista implica que ha de existir una tesis de relevancia última (que sea coherentemente concebible y accesible una especificación previa, exhaustiva, de las propiedades éticamente relevantes, es decir, del universo de los casos posibles éticamente relevantes). Esto no puede ser aceptado. La idea de una tesis de relevancia última está mal formada. ${ }^{17}$

\footnotetext{
${ }^{16}$ Un razonamiento falaz no es un razonamiento: sólo tiene la apariencia de un razonamiento.

${ }^{17}$ Contrariamente a lo afirmado en B. Celano, “"Defeasibility” e bilanciamento. Sulla possibilità di revisioni stabili”, en Ragion pratica, n. 18, 2002, p. 236. (Un punto justamente subrayado por Redondo, RyN, n. 19.)
} 
El argumento se sustenta en dos consideraciones: (1) los problemas prácticos surgen típicamente de la interacción entre una pluralidad de individuos; (2) una acción es susceptible de una pluralidad de descripciones, y es vista por el agente (o por otros) bajo una o más descripciones particulares (no necesariamente las mismas).$^{18}$ Estos fenómenos son ambos reconducibles al hecho de que la mente humana está dotada de intencionalidad.

Los problemas prácticos (los casos respecto de los cuales se plantea el problema de cómo actuar) implican típicamente una pluralidad de individuos (entre ellos el agente). Qué propiedades sean relevantes en un cierto caso en miras a la decisión de cómo actuar es algo que depende también de la interacción entre los agentes involucrados o de sus comportamientos pasados: depende, pues, no solamente del estado actual del caso, sino también de su historia (del recorrido a través del cual se ha arribado a la situación actual). ${ }^{19}$ (El hecho de que el que yo haya prometido a Cayo hacer A constituya o no ahora una razón para mantener mi promesa puede depender de cómo Cayo se ha comportado en el pasado, frente a mí -o frente a Sempronio, con quien, si bien no lo conoce personalmente, comparte algunas convicciones importantes, por ejemplo, convicciones sobre la cuestión de si deben mantenerse las promesas, y en todo caso cuándo). Y el conjunto de las combinaciones de las propiedades potencialmente relevantes, teniendo en cuenta la historia del caso, no puede identificarse exhaustivamente. No en el sentido de que, dada su complejidad, sería necesario una computadora muy potente para articular todas las posibilidades. No puede en principio identificarse exhaustivamente porque, en virtud del hecho de que los agentes involucrados están dotados de intencionalidad, pueden tornarse relevantes (y normalmente son relevantes) en la interacción (y en su historia) las

\footnotetext{
${ }^{18}$ G. E. M. Anscombe, Intention, Blackwell, Oxford, 1957 (1972), p. 11.

${ }^{19}$ De ahí la tesis, difundida entre los defensores del particularismo, de que la racionalidad práctica sea racionalidad "narrativa". Que las razones para la acción dependan, no tanto de la situación actual, sino también del recorrido que ha conducido a ella (de su historia) es una primera especificación (aunque insuficiente) del sentido de esta caracterización.
} 
intenciones de uno o más de ellos, estados intencionales que tienen por objeto otros estados intencionales (estados intencionales nidificados), sistemas de estados intencionales de más niveles, recíprocamente conectados (sea diacrónicamente, sea sincrónicamente), y así sucesivamente. Puede suceder que sean relevantes, por ejemplo, las creencias en torno a las intenciones o las creencias de los demás, las expectativas sobre sus ulteriores actitudes y comportamientos, y así hasta el infinito. Y entre los estados relevantes pueden subsistir relaciones relativas a su contenido o relaciones causales. (Puede ser relevante si Ticio espera o no que yo mantenga la promesa, y esto puede depender de qué cosa espera que yo espere de él, a la luz del cómo me he comportado en un caso pasado -de acuerdo a lo que él cree; en efecto, no obstante, en ese caso me he comportado de ese modo en particular para inducirlo a esperar, entonces, que yo espere una cierta cosa de él, etcétera).

A esto se suma la circunstancia de que una acción se presenta al agente o a otros bajo una o más de una descripción de entre una pluralidad indefinida de descripciones posibles, y puede presentarse a individuos diferentes bajo descripciones diferentes (puede suceder que el agente ignore que lo que está haciendo cae bajo una cierta descripción, que resulta evidente a los ojos de otro individuo). No hay razones para pensar que el vocabulario de las descripciones de las acciones posibles sea limitado. ${ }^{20}$

Esta circunstancia se combina con la precedente: la historia de la interacción entre una pluralidad de individuos está constituida también por estados intencionales (de nivel creciente, etc.) cuyo contenido comprende descripciones diferentes de las acciones relevantes, descripciones bajo las que tales acciones son percibidas (o se percibe que se las percibe, o se espera que se espere que se las perciba, etcétera) sólo por algunos de los individuos involucrados y no por otros. Bajo qué descripciones se le presenta

${ }^{20}$ La misma posición es adoptada, en contra de la idea de una tesis de relevancia última, en J. J. Moreso, "Dos concepciones de la aplicación de las normas de derechos fundamentales", inédito, 2004. 
a Ticio una acción (o Cayo piensa que se le presenta a Ticio, etc.) es una cuestión relevante a los fines de la narración de los sucesos que han conducido a la situación actual. Y esta pluralidad indefinida de descripciones posibles, y de estados intencionales que pueden constituir su contenido, determina (o puede dejar indeterminada) la descripción de la situación actual.

La interacción humana -real o pensada- produce una pluralidad indefinida de propiedades potenciales relevantes, y de historias en las que tales propiedades resultan instanciadas. Esta multiplicidad no es computable. $\mathrm{Si}$, al delinear las propiedades de un caso, se toma en consideración su historia, no hay límite a la posibilidad de situaciones nuevas. ${ }^{21}$

\section{La superioridad del particularismo}

Cuando hemos de enfrentarnos a las razones morales, por lo tanto, la alternativa entre universalismo y particularismo no es una cuestión de elección -no se trata de una cuestión puramente normativa o valorativa. ${ }^{22}$ Se trata

\footnotetext{
${ }^{21}$ ¿Esto quiere decir que una tesis de relevancia última no es (en modo alguno) lógicamente posible? Estoy inclinado a creerlo. Pero sea como sea que se responda (no existen dudas, por ejemplo, de que un Dios creador y omnipotente, dotado de recursos mentales infinitos, tendría bajo sus ojos por toda la eternidad la tesis de la relevancia última), la idea de una tesis de relevancia última que sea lógicamente posible pero, por hipótesis, epistémicamente inaccesible (idea que subyace en Redondo, $R y N$, n. 19) carece de utilidad desde el punto de vista de una reconstrucción de la forma del razonamiento práctico. El razonamiento práctico es un proceso epistémico (volveré mas tarde sobre este punto).

${ }^{22}$ Redondo indica un argumento que podría justificar la conclusión de que entre particularismo y universalismo no se puede, en última instancia, no escoger. La alternativa entre particularismo y universalismo es, escribe Redondo, una alternativa «fundamental (básica)», de modo que «resulta difícil encontrar argumentos (i.e. razones) concluyentes a favor o en contra de una de estas posiciones sin presuponer lo que está en cuestión. Es decir, sin presuponer la propia concepción a favor de la cual se está tratando de argumentar» (RyN, Reflexiones finales; véase el pasaje correspondiente de LR, Concluding Remarks, transcripto infra, Apéndice I). Sin embargo, éste es un argumento que vale respecto de todas, o casi todas, las alternativas filosóficas cruciales. Habitualmente, lo máximo que se puede hacer es poner de manifiesto el poder explicativo de una posición sobre la base de consideraciones que, en última instancia, la presuponen. En el texto, la superioridad conceptual, analítica y explicativa, del modelo particularista ha sido justificada e ilustrada sobre la base de la imposibilidad de una tesis de
} 
más bien de una cuestión conceptual y, en tanto conceptual, normativa: una cuestión relativa a qué forma de razonamiento es correcta o razonable. El razonamiento práctico, sin efectuar restricciones, es particularista. ${ }^{23} \mathrm{Y}$ si bien es posible que respecto de ciertos ámbitos se adopte un modelo de decisiones basado en reglas (rectius, un estilo de razonamiento que imita al razonamiento universalista), se tratará no obstante de ámbitos de decisión determinados, circunscriptos. Y la decisión de adoptar respecto de ese ámbito de decisiones una estrategia (para-)universalista será no obstante provisoria -sujeta a la posibilidad de ser revocada sobre la base de circunstancias excepcionales. Se tratará, en suma, de islas universalistas en un mar particularista.

En otras palabras: es verdad que, respecto de ámbitos circunscriptos de decisión, podemos escoger entre adoptar una estrategia de decisión universalista o particularista, pero esa decisión se adopta sobre bases particularistas. La alternativa entre razonamiento universalista y particularista está gobernada por razones particularistas. El razonamiento moral (el razonamiento práctico, sin restricciones) tiene la forma de un archipiélago de ámbitos de decisión universalistas (ámbitos de decisión que imitan las decisiones universalistas) en un océano particularista.

Esto no quiere decir que la ética sea irracional, o a-racional. El temor de que la tesis particularista constituya una amenaza para la posibilidad del razonamiento práctico -que llevada al extremo, significaría que no pueda

relevancia última. Esta es una consideración relativamente independiente de la conclusión, gracias a lo cual es posible ampliar el círculo. Pero si también tuviera que concluirse que la tesis según la cual la idea de que una tesis de relevancia última está mal planteada presupone, en el fondo, el particularismo (que, por ejemplo, esta tesis parece convincente sólo si se está dispuesto a aceptar una concepción particularista del razonamiento práctico), esta conclusión no sería preocupante. Los argumentos filosóficos son, comúnmente, circulares en este sentido. (Lo cual, quizás, arroja una siniestra sombra sobre los argumentos filosóficos. Pero esa es otra historia). ${ }^{23}$ Para una formulación más articulada de esta conclusión y argumentos ulteriores que la abonan, B. Celano, "Particolarismo, caratterizzazioni di desiderabilità, pluralismo etico. Considerazioni sulla forma del ragionamento pratico", trabajo presentado en la Universidad Pompeu Fabra, Barcelona (España), 2 de abril de 2004, de próxima publicación en Ragion pratica (vers. provisoria en http://dpds.onetxp.com/downloads/downloads.asp, PART_TXT). 
considerárselo un "razonamiento"- nace a partir de un malentendido. ${ }^{24} \mathrm{El}$ modelo particularista es perfectamente compatible con la posibilidad y sensatez de la investigación ética sustancial; específicamente, con una concepción holística y coherentista de la argumentación ética sustancial. No excluye en absoluto la posibilidad o legitimidad de generalizaciones confiables: proyecciones o extrapolaciones de casos pasados (o actuales) a casos futuros (o posibles). Sencillamente, nada garantiza que nuestras generalizaciones den en el blanco -que no se revelen, inesperadamente, como sujetas a la necesidad de ser revisadas a la luz de circunstancias extraordinarias.

Por consiguiente, en el ámbito moral no tenemos elección: el razonamiento moral es particularista. Si en el ámbito jurídico la alternativa entre universalismo y particularismo depende de razones morales, y si ésta última tiene carácter particularista, tampoco en el ámbito jurídico tendremos en última instancia elección: el modelo particularista sería (conceptual y, al mismo tiempo, normativamente) prioritario. En síntesis, también el razonamiento jurídico sería un archipiélago de esferas de decisiones para-universalistas (esferas de decisión en las que las razones disponibles imitan a las razones universalistas) en un océano de razones particularistas.

\section{Por qué a veces no es necesario distinguir entre las reglas y sus formulaciones}

Ya he sostenido en otro lugar algunas de las ideas contenidas en los párrafos precedentes. ${ }^{25}$ Redondo dirige una objeción contra esta formulación de mi posición. Mi argumentación estaría, según Redondo, viciada por una omisión: no tendría en cuenta la distinción entre una regla y su formulación $y$, en consecuencia, no tomaría en consideración la posibilidad de distinguir entre la revisión de una regla y la revisión de una de sus formulaciones. ${ }^{26}$

\footnotetext{
${ }^{24}$ También en este punto remito al ensayo citado en la nota precedente.

${ }^{25}$ B. Celano, “"Defeasibility” e bilanciamento. Sulla possibilità di revisioni stabili”, cit. ${ }^{26}$ RyN, n. 19; LR, n. 17.
} 
¿Qué significa entonces no distinguir entre la formulación de una regla y la regla misma (su contenido normativo)? ¿Cuándo es posible, y necesario, realizar esa distinción?

La distinción tiene una relevancia crucial, y es necesario realizarla, cuando se halla disponible y resulta accesible una tesis de relevancia -cuando ya está fijada de algún modo la tesis de relevancia relativa al conjunto de reglas que se está tomando en consideración. En tal caso, la regla, en su reconstrucción completa (en su auténtico contenido) se encontrará determinada en cuanto a sus condiciones de aplicación por la tesis de la relevancia. En cambio, sus formulaciones podrían ser parciales o imprecisas. Se trata, en efecto, de la distinción entre la regla, por un lado, y el modo en el que se la concibe o se la comprende, por el otro -entre el objeto, y lo que sabemos o creemos saber sobre él. El hecho de que nuestras opiniones acerca del contenido de la regla sean revisables no significa que la propia regla sea revisable: la necesidad de revisión es sólo epistémica, no afecta al objeto de nuestras opiniones (no afecta a la regla, sino solamente al modo en que a veces la formulamos).

De acuerdo. Pero todo esto está sujeto a una condición: que se encuentre disponible y resulte accesible una tesis de relevancia. En el caso del razonamiento moral, como hemos visto, no existe una tesis última de relevancia (la idea misma estaría mal formada). En otras palabras, el objeto "regla" (la identidad del contenido normativo) está fijado por una tesis de relevancia. En el caso del razonamiento moral, esa tesis debería ser (si se quiere bloquear la conclusión particularista) una tesis de relevancia última. Pero no existe una tesis de relevancia última. Por lo tanto, en el caso del razonamiento moral, no es necesario -porque no es posible- distinguir entre las reglas y nuestras opiniones acerca de ellas. Las reglas no existen: son generalizaciones (proyecciones del presente al futuro, extrapolaciones de lo actual a lo posible) más o menos fiables, por lo que no tendría sentido distinguir entre la revisión de la generalización, por una parte, y la revisión de lo que de ella sabemos (de nuestra opinión respecto de su contenido), por la otra. Cuando revemos nuestra opinión acerca de la regla (en el sentido indicado, 
esto es, la generalización, extrapolación o proyección que guía nuestras expectativas) revemos la regla. El razonamiento moral se proyecta al infinito; es él mismo un proceso epistémico. ${ }^{27}$

En otras palabras, cuando tomamos una decisión, su contenido es compatible con una pluralidad indefinida de reglas. En tal caso, ¿qué regla estamos siguiendo? ¿Se trata de la misma regla que hemos aplicado en el caso pasado? En la medida en que quede abierta la posibilidad de revisiones o refinamientos ulteriores, esas preguntas están mal planteadas. No existe para ellas una respuesta determinada. ${ }^{28}$ (Las dos preguntas tendrían sentido sólo si se asumiera la posibilidad de una tesis de relevancia última, o sea, de una revisión estable). El estándar cuya formulación constituye el resultado de la decisión contiene, ineludiblemente, cláusulas abiertas, en las que aparecen (en forma explícita o implícita) términos y conceptos éticos. ${ }^{29}$

Como parece obvio, las cosas son diferentes cuando se toma en cuenta un conjunto predeterminado y circunscrito de prescripciones dotadas de una o más formulaciones canónicas, respecto de las cuales es posible construir una tesis de relevancia (esto es, ses posible asumir que se halla ya fijada de

\footnotetext{
${ }^{23}$ Esto no quiere decir, obviamente, que no sea posible distinguir entre una generalización, por un lado, y una formulación en particular de ella, por otro lado (y, por lo tanto, entre revisiones de las generalizaciones y revisiones de una de sus formulaciones). Quiere decir, sin embargo, que no es esta posibilidad la que está en cuestión en la alternativa entre particularismo y universalismo (en el caso de las razones morales). Esa distinción es del todo marginal, y no resulta relevante a los fines de la cuestión de si el razonamiento práctico tiene carácter particularista o universalista. ${ }^{24} \mathrm{Cfr}$. para una argumentación similar, S. Blackburn, Ruling Passions. A Theory of Practical Reasoning, Clarendon Press, Oxford 1998, p. 309. Cfr. también ivi, p. 226, n. 22 ("No mentiré jamás, a menos que..." es un principio universal «provided the dots can eventually be filled in»; «the particularist will deny that the dots can be filled in, and hence deny that universal principles are even implicitly involved in practical reasoning»). El recurso a esta línea de argumentación resurge en J. McDowell, Virtue and Reason (1979), en McDowell, Mind, Value, and Reality, Harvard University Press, Cambridge (Mass.) 1998. Cfr. también R. Crisp, "Particularizing Particularism", en B. Hooker, M. Little (eds.), Moral Particularism, Clarendon Press, Oxford 2000, pp. 25-6.

${ }^{25}$ Cfr. D. McNaughton, P. Rawling, "Unprincipled Ethics", en Hooker, Little (eds.), Moral Particularism, cit.; J. J. Moreso, "El positivismo jurídico y la aplicación del derecho", inédito, 2004, de próxima aparición en Materiali per una storia della cultura giuridica.
} 
algún modo una tesis de relevancia). Parecería que los conjuntos de reglas jurídicas pueden satisfacer esta condición. Y, podría decirse, la objeción de Redondo según la cual mi argumento estaría viciado por la falta de distinción entre (revisiones de) reglas y (revisiones de) formulaciones de reglas, concierne precisamente a las reglas jurídicas. Su límite está, y pretende estar, acotado a la hipótesis de que se trata de reglas jurídicas (vale, y pretende valer, sólo respecto de la hipótesis de que el conjunto de las reglas tomadas en consideración es un conjunto de reglas jurídicas).

Quizás. Pero, a decir verdad, en el escrito contra el cual Redondo dirige la objeción que aquí se examina yo precisaba explícitamente que el objeto de mis consideraciones estaría dado por los casos en los cuales las normas jurídicas (específicamente, principios constitucionales que establecen derechos, valores, etc.) son tratados como derrotables (como requiriendo revisión) sobre bases éticas -es decir, sobre la base de consideraciones morales (los casos relevantes para mi análisis serían los casos de «derrotabilidad en base a consideraciones morales sustanciales» o «derrotabilidad sobre bases éticas»). ${ }^{30}$ En casos así, precisamente, la distinción que reclama Redondo no juega ningún papel porque, como hemos

${ }^{30}$ B. Celano, ““'Defeasibility” e bilanciamento. Sulla possibilità di revisioni stabili”, cit., pp. 226-8. Subrayaba explícitamente (ibidem), por otra parte, que la derrotabilidad sobre bases éticas es solamente una de las fuentes de la idea de que el discurso normativo sea, o deba ser, considerado como derrotable; y mencionaba explícitamente la idea de que la derrotabilidad puede tener raíces en la disfunción entre lo que una autoridad normativa expresamente prescribe y lo que (sobre la base, por ejemplo, de su intención efectiva o contrafácticamente reconstruida) se puede creer que está implícito en lo que ella ha dicho (retomaba, a propósito, la noción de «derrotabilidad pragmática», elaborada por C.E. Alchourrón, "On Law and Logic", Ratio Juris, 9, 1996, pp. 339-44). En nota (““"Defeasibility” e bilanciamento. Sulla possibilità di revisioni stabili", cit., p. 227) mencionaba la circunstancia de que «nociones diferentes de derrotabilidad (en el discurso normativo) se diferencian [también] en lo que se refiere a la cuestión de si al ser derrotables son normas, formulaciones normativas o proposiciones normativas», y puntualizaba explícitamente que «respecto de la noción de derrotabilidad aquí utilizada -derrotabilidad sobre bases morales sustantivas- lo que han de considerarse derrotables son, antes que nada, las normas». 
visto recién, en el ámbito moral no es posible distinguir entre nuestras opiniones sobre la regla (rectius, la generalización) y la regla misma.

Es verdad que si dispusiéramos en el ámbito jurídico de una teoría de la interpretación que consintiese en fijar el contenido de la regla de manera independiente respecto de la historia de sus aplicaciones (mediante, por ejemplo, la intención del legislador), la distinción entre una regla y sus diversas formulaciones podría muy bien desarrollar un papel de importancia crucial. Bien podría darse el caso, en efecto, que lo que se encuentre en cuestión sea la revisión de una formulación de la regla a la luz de su significado rectamente comprendido (por ejemplo, la explicitación de aquello que se halla implícito en la enunciación efectiva del legislador, sobre la base de su intención no expresada). Pero, en primer lugar, y tal como lo he recordado recién, no era ésta la hipótesis respecto de la cual fueron vertidas mis consideraciones. (Por ello, la objeción de Redondo no alcanza a mi argumento). Y, en general, la idea de una teoría de la interpretación que fije el significado de una expresión independientemente de la historia de sus aplicaciones me impresiona por su extravagancia. Las teorías del significado ordinarias, es decir, las teorías del significado respecto de enunciados ordinarios (descriptivos y no descriptivos) como, por ejemplo, "Esto es una lapicera", o "Las mesas redondas son un poco incómodas", no son así. Que pueda serlo una teoría del significado de las disposiciones jurídicas (y, no obstante, ello no sea así respecto de aserciones como "Esta es una lapicera”) me parece realmente extraño. Y, en todo caso, más extraña me parece esta hipótesis respecto de las disposiciones constitucionales que establecen derechos, valores y principios. Verdaderamente, en este caso el legislador (el constituyente) tiene en mente muchas cosas, y por maldad (o quizás para ponerlo a prueba) no ha querido decirlas explícitamente desde el vamos.

\section{Apéndice I. La alternativa entre particularismo y universalismo según Redondo}

¿De qué modo ve Redondo la alternativa entre particularismo y 
universalismo? En el párrafo introductorio de su trabajo, Redondo afirma que es oportuno distinguir «tres tipos de discursos -y de discusiones- que, aun estando relacionados entre sí, comportan objetivos claramente diversos»: «discursos analítico-conceptuales, descriptivo-explicativos y evaluativojustificativos». Puntualiza a continuación que «la oposición entre universalismo y particularismo tal como aquí la analizo es expresión de un desacuerdo filosófico, entendido como desacuerdo entre modelos conceptuales»; y que «el presente trabajo consistirá exclusivamente en un tentativo de establecer cuáles son dichos modelos para luego intentar reconocer qué teorías jurídicas se comprometen con una u otra posición».

Redondo prosigue diciendo que «existen diversos modos de entender el análisis conceptual» («y es posible que en la presente discusión este subyacente un desacuerdo también sobre este punto», agrega). Y declara que, en su trabajo, universalismo y particularismo serán entendidos «como dos modelos conceptuales ideales que, si muestran ser lógica y empíricamente posibles, i.e. internamente coherentes y de implementación factible por parte de sujetos reales, pueden defenderse o justificarse sobre la base de consideraciones de valor». ${ }^{31}$

${ }^{31}$ «En pocas palabras -prosigue Redondo (ibidem)- asumiré que estamos ante dos reconstrucciones racionales de una serie de conceptos, y no ante dos análisis hermenéuticointerpretativos que explican o dan sentido a una práctica argumentativa, más o menos extensa, tal como los sujetos de esa práctica la conciben» (parecería que ésta es la diferente concepción del análisis conceptual, que se señalara un poco antes). Se trata, por lo tanto, de «tratar las posiciones presentadas como modelos ideales». Esta es de hecho la única posibilidad que «puede revestir interés en un estudio de teoría general del derecho». Es posible descubrir la existencia de prácticas argumentativas consolidadas diferentes, y existen «enteros sectores de los ordenamientos jurídicos en los que los operadores tienden a seguir reglas en sentido "estricto", mientras que en otros, ya sea de facto o en virtud de una expresa autorización jurídica, la práctica del "distinguishing" es ampliamente usada». «Desde un punto de vista fenomenológico es factible ofrecer ejemplos de prácticas en las que los operadores del derecho, y especialmente los jueces, se ven a si mismos jugando roles diferentes que avalan alternativamente distintos modelos argumentativos». Conclusión: «la discusión que aquí presento reviste interés para la teoría jurídica sólo en la medida en que ella se interprete como un debate entre dos modelos ideales, $\mathrm{o}$ patrones, bajo los cuales es posible analizar y practicar el derecho». 
Parece entonces que, según Redondo, particularismo y universalismo son (al menos en lo que se refiere al ámbito de las razones jurídicas) dos modelos en sí coherentes (en el plano conceptual, o analítico-conceptual, uno tan válido como el otro), y que la elección entre ellos sería una elección a cumplimentar sobre la base de consideraciones valorativas (consideraciones normativo-valorativas sustanciales). Esta conclusión se confirma con lo que Redondo escribe en las Reflexiones Finales de su trabajo. Aquí, nuevamente, Redondo distingue entre «problemas y discursos analítico-conceptuales, descriptivo-explicativos y evaluativo-justificativos». («tres niveles de discusión: el conceptual, el evaluativo y el empírico»; LR, Concluding remarks). Redondo afirma que en el nivel conceptual «ambos modelos ofrecen una reconstrucción coherente de la noción de razón justificativa. Dado el carácter básico de esta cuestión, resulta difícil encontrar argumentos (i.e. razones) concluyentes a favor o en contra de una de estas posiciones sin presuponer lo que está en cuestión. Es decir, sin presuponer la propia concepción a favor de la cual se está tratando de argumentar». (En el nivel conceptual «ambos modelos ofrecen un enfoque coherente del concepto de razón y resulta difícil encontrar argumentos filosóficos concluyentes a favor o en contra de alguno de ellos sin presuponer la propia concepción de las razones que se pretende defender. Esto implica que es lógicamente posible concebir a un ordenamiento jurídico como ajustado a una o la otra concpeción»; LR, Concluding Remarks).

Puesto que el derecho depende de conductas y comportamientos humanos, prosigue Redondo, «a fin de elegir el mejor enfoque filosófico para analizar el derecho en términos de razones para la acción, es imprescindible pasar a un nivel evaluativo de discurso en el que se hagan explícitos los valores que cada uno de estos modelos promueve, y las ventajas o desventajas que pueden resultar de su implementación». «En otras palabras - concluye - admitido que ambas propuestas ofrecen modelos posibles para comprender el derecho desde un punto de vista práctico, el tratamiento de 
las normas jurídicas como constituyendo uno u otro tipo de razón es materia de decisión que deberá ser justificada sobre la base de valores o ventajas externas a dichos modelos»».

(En LR, Concluding Remarks, encontramos el mismo argumento, formulado en términos ligeramente diferentes. Redondo distingue, además de la cuestión conceptual y la descriptiva, una tercera cuestión, «cómo deberíamos concebir el derecho». Si planteamos este interrogante, escribe, «es importante destacar que cuando decidimos tratar, o proponemos que se trate, a una institución como el derecho como si generara una clase especial de razones para la acción, estamos asumiendo ciertos valores. El universalismo ordinariamente se vincula con valores como la certeza, la predecibilidad, la equidad formal, etc. El particularismo, por su parte, si vincula primordialmente con la equidad, la flexibilidad, la imparcialidad, etc. Eventualmente, a fin de escoger el mejor enfoque filosófico de las razones jurídicas, debemos adentrarnos en el nivel evaluativo del discurso y establecer explícitamente los valores que cada modelo asume así como las ventajas y desventajas que pueden obtenerse a través de su implementación». Redondo concluye que «el carácter particularista o universalista de las rezones jurídicas depende del modo en que los operadores jurídicos conciban al derecho. Dado que ambos modelos son lógica y empíricamente viables, podría tratarse de una cuestión de elección. Una elección que, seguramente, está ligada a importantes consecuencias conceptuales y sustantivas».)

\section{Apéndice II. Particularismo y razones pro tanto}

Mi visión de la distinción entre particularismo y universalismo difiere de la de Redondo en un punto de crucial importancia (y esta divergencia aflora varias veces en los párrafos precedentes). Según Redondo (que sobre este punto no se aparta del modo en que la mayoría de los autores participantes del debate contemporáneo trazan la distinción), la tesis de que algunas razones para actuar sean generales pero pro tanto (expuestas, por tanto, a la posibilidad 
de ser overridden por otras razones y, a veces, sujetas a ponderación), es incompatible con el particularismo. A mi modo de ver, en cambio, la diferencia entre esta posición $(\mathrm{o}$, al menos, una particular versión de ella presentada abajo) y la posicion particularista se desvanece. La diferencia significativa es, sobretodo, aquella que se da entre el particularismo y la tesis de las razones pro tanto, por una parte, y la tesis según la cual el razonamiento práctico consiste en la aplicación de auténticas reglas (que no admiten ni defeaters ni la posibilidad de ser overriden), por el otro. Me explico.

Considérese la hipótesis siguiente: las razones para actuar son plurales, a menudo conflictivas, inconmensurables, indeterminadas; algunas razones para actuar son generales (algunas consideraciones tienen siempre relevancia práctica, y tienen siempre la misma polaridad: valen siempre como razones, ya sea a favor o en contra, de una cierta línea de conducta); en cualquier caso, no obstante, resultan además aplicables otras razones (comúnmente, razones en conflicto entre ellas, o inconmensurables o indeterminadas), y la decisión acerca de cómo actuar -sobre qué es aquello para lo que se tienen mayores razones para actuar, considerando todos los factores relevantesdepende en ultima instancia de una ponderación de las razones a favor y en contra (no existe ningún orden predefinido de prioridad entre valores ni entre las razones que en ellos se fundan).

Llamaré a esta imagen del razonamiento práctico "modelo de la ponderación". El modelo de la ponderación resulta, a primera vista, incompatible con el particularismo. La tesis particularista, de hecho, afirma: lo que en un cierto caso constituye una razón para hacer $A$ puede no ser en otro caso una razón para hacer $A$, o bien puede ser una razón para no hacer $A$. (Cuando en un cierto caso el hecho de que $p$, o la propiedad $P$, sea una razón para hacer $A$, puede muy bien suceder que en otro caso el hecho de que $p, \mathrm{o} P$, no sea una razón para hacer $A$ o sea una razón para no hacer $A$ ). Para el modelo de la ponderación hay razones generales, aunque sólo sean razones pro tanto (el modelo de la ponderación es, en efecto, una forma de 
universalismo pluralista). El particularista se orienta a la negación de esta tesis (al menos con respecto a la gran mayoría de las razones). ${ }^{32}$

La idea de que el razonamiento práctico consiste en la individualización $\mathrm{y}$ en la ponderación (caso por caso) de razones generales pro tanto (que consiste en la aplicación a ciertos casos de principios no absolutos ${ }^{33}$ pero "contribuyentes" y en su ponderación caso por caso) es, en efecto, uno de los objetivos polémicos de los defensores del particularismo. La tesis particularista (bien puede ocurrir que, aunque el hecho de que p sea en cierta ocasión una razón para hacer $A$, en otra ocasión no sea una razón para hacer $A$, y en otra quizás sea una razón para no hacer $A$ ) excluye las razones generales, aunque sean pro tanto (y sujetas a veces a ponderación).

Pero aquí es posible preguntar ¿hay efectivamente una diferencia (una diferencia significativa, apreciable) entre las dos posiciones -entre la tesis de que existen razones generales, pero sólo pro tanto (y que la decisión depende, en cada caso, de una ponderación entre ellas), por una parte, y la tesis particularista, por la otra? ¿O más bien se trata de formulaciones diferentes de la misma posición? Se podría sostener que el universalista pluralista, que admite la posibilidad de razones (razones pro tanto) conflictivas, inconmensurables, indeterminadas, y cree que el conflicto ha de resolverse en cada caso sobre la base del "peso" de las razones relevantes (esto es, que recurre a la idea de ponderación) no es significativamente distinguible del particularista. ¿Cuál es la diferencia efectiva entre las dos posiciones? El particularista aduce contraejemplos: en ciertos casos, P es

${ }^{32}$ Cfr. para este contraste J. Dancy, Moral Reasons, Blackwell, Oxford 1993, p. 60; Id., "Moral Particularism", en E. N. Zalta (ed.), The Stanford Encyclopedia of Philosophy (Summer 2001 Edition), http://plato.stanford.edu/archives/sum2001/entries/moral-particularism/, pp. 4, 7-8; R. Shafer-Landau, "Moral Rules", en Ethics 107 (1997), pp. 588-9; B. Hooker, "Moral Particularism: Wrong and Bad", en Hooker, Little (eds.), Moral Particularism, cit., pp. 1-6; Redondo, RyN, par. I.1.

${ }^{33}$ Un principio absoluto «can never be overridden, and it overrides all possibly competing considerations» (Shafer-Landau, "Moral Rules", cit., p. 585; cfr. también Dancy, "Moral Particularism", cit., pp. 2-3). 
una razón para hacer A; en otros, no lo es en absoluto, o es absolutamente una razón para no hacer A (invierte su polaridad). Pero los contraejemplos del particularista pueden ser redescritos en clave universalista, de modo que se ponga de manifiesto que existen ciertas razones generales cuyo peso relativo puede variar considerablemente. ${ }^{34}$ Una vez que se reconoce que las razones son múltiples, conflictivas, inconmensurables e indeterminadas, debido a que radican en valores (o valoraciones) múltiples, conflictivas e inconmensurables, y que, en caso de conflicto, normalmente no existe un orden lexicográfico de prioridad ni existen reglas de resolución predeterminadas, una vez que se reconoce todo esto, que se admita o se rechace la posibilidad de que existan razones generales (pero sólo pro tanto) no constituye, me parece, ninguna diferencia seria. (Es cierto que la ponderación puede concretarse en una regla, pero esa regla será, a su vez, revisable: no existe una tesis de relevancia última.) Las dos posiciones son, en los hechos, indistinguibles.

Es cierto que esta forma de universalismo, pluralista (que admite la posibilidad de conflicto o inconmensurabilidad entre las razones y reconoce la necesidad de una ponderación entre ellas) excluye la posibilidad de que, ceteris paribus, lo que en un caso constituye una razón para hacer A, en otro caso puede no serlo (o puede ser una razón para no hacer A). Pero admite que "los factores ulteriores" no son los mismos (cetera no son constantes) y reconoce que, al variar cetera, el peso relativo de una razón puede variar. En la medida en que el caso sea suficientemente anómalo, el peso de una razón puede devenir ínfimo y, en el caso límite, nulo. ${ }^{35} \mathrm{La}$ idea

\footnotetext{
${ }^{34}$ Cfr. por ejemplo, Hooker, "Moral Particularism”, cit., pp. 7 ss. El punto es formulado con claridad en Shafer-Landau, "Moral Rules", cit., pp. 590, 608.

${ }^{35}$ En el modelo de la ponderación, las razones tienen un peso sólo relativo. La tesis universalista que estamos considerando consiste en sostener que cierta propiedad tiene siempre una cierta relevancia y polaridad (militan siempre a favor o en contra de una cierta acción), no que tienen siempre un cierto peso absoluto. Esta tesis seria absurda, si no por otras razones, porque la cuestión del peso es sólo una metáfora, lo cual hace que la imagen de un peso absoluto unido a cada razón carezca de contenido. Las razones asumen un peso sólo al contrastárselas unas con otras y en su ponderación (Cfr. Shafer-Landau, "Moral Rules", cit., p. 598.)
} 
de que el hecho de que $p$ (o la propiedad $P$ ) sea pro tanto una razón para hacer $A$ no debe ser entendida en el sentido de que si (y siempre que) $P$ es la única propiedad relevante del caso, tenemos una razón concluyente para hacer $A$. Esta idea es absurda. ${ }^{36}$

Se podría objetar que hay, no obstante, una diferencia entre tener un peso relativo muy bajo, incluso ínfimo, y no tener ningún peso; ${ }^{37}$ y que el decir que una razón puede tener en un caso "un peso ínfimo -en el caso límite, ningún peso" es sólo un expediente verbal. Pero el punto es, precisamente, que en última instancia la alternativa entre particularismo y universalismo pluralista termina dependiendo de cómo se deciden alternativas del tipo "Cuando la madre ahoga al niño porque sigue gritando y no logra que se calle, ¿el malestar y la rabia producto del llanto son realmente una razón de peso ínfimo para ahogar al niño o no lo son en absoluto?; 38 "Cuando nos ponemos a escuchar Like a Rolling Stone al llevar a un amigo al hospital porque de repente ha sufrido un infarto, ¿la belleza de Like a Rolling Stone es una razón, aunque de peso ínfimo, para permanecer donde uno se encuentra hasta que termine el tema o no es en absoluto una razón?”. Preguntas como éstas son artificiales, y no me parece que merezcan una respuesta seria. No sólo eso: la respuesta que se escoja es, a mi entender, del todo irrelevante. No es posible que una alternativa teóricamente significativa dependa de cómo se responde a preguntas como éstas. ${ }^{39}$

\footnotetext{
${ }^{36}$ Dancy, "Moral Particularism", cit. p. 8.

${ }^{37}$ Cfr. Shafer-Landau, "Moral Rules", cit., p. 585.

${ }^{38}$ Este ejemplo es de G. Watson.

${ }^{39}$ Pero podría decirse que la tesis particularista no afirma solamente que la misma propiedad pueda ser a veces una razón para hacer A y otras una razón para no hacer A (puede invertirse, en casos diversos, su polaridad). Y esta última posibilidad parecería que se encuentra excluida del modelo de la ponderación. (La idea de que, en un cierto caso, una razón pro tanto pueda tener un peso ínfimo, nulo en el caso límite, sólo da cuenta de la primera hipótesis, no de la segunda). A esta objeción respondo así: la polaridad de una propiedad depende de las ulteriores características del caso; en conjunción con características diversas, la misma propiedad puede valer a veces como una razón para hacer A y otras como una razón para no hacer A. (Los ejemplos empleados por el particularista para ilustrar esta posibilidad se prestan para ser
} 
Por consiguiente, no me parece que exista una diferencia efectiva entre una concepción del razonamiento práctico que lo interprete como consistente en la individualización de razones que pueden en ciertos casos no tener ningún peso, o tener un peso contrario, por un lado, y una concepción del razonamiento práctico que lo interprete como consistente en la ponderación de razones pro tanto, cuyo peso puede resultar, en el caso límite, nulo (universalismo pluralista). La tesis particularista ciertamente no es incompatible con el modelo de la ponderación así entendido.

descriptos de este modo.) ¿Es incompatible esta respuesta con el modelo de la ponderación? No, siempre que se comprenda (como se lo ha hecho aquí) la individualización de razones pro tanto como el fruto de generalizaciones (proyecciones, extrapolaciones) revisables, a la luz de las ulteriores características del caso. La constelación de los valores (y, por lo tanto, de las razones) relevantes en un cierto caso puede tener una estructura tal que haga que la circunstancia de que una cierta acción quede comprendida por un cierto valor (y sea, pro tanto, buena) sea una razón para no cumplir el acto en cuestión. Esto depende de la forma del conflicto entre los valores involucrados. (Por ejemplo, que un acto sea gentil es normalmente una razón para llevarlo a cabo, pero puede darse el caso de que haya razones para no ser gentil. Que un acto sea placentero puede, para un asceta, ser una razón para abstenerse de realizarlo; pero el asceta no debe necesariamente negar que lo que es placentero es bueno.) La hipótesis relevante, se advierte claramente, es que en ciertos casos se tiene una razón (fundada en el valor V1) para no hacer aquello que se tiene una razón (fundada en V2) para hacer, precisamente porque se tiene esta razón (fundada en V2) para hacerla. Esto depende de la relación que, en este caso, subsiste entre V1 y V2. En casos como estos la pregunta: “ ¿E1 hecho de que hacer A sobre la base de V2 constituya una razón para hacerlo que, sin embargo, es superada (overridden) por una razón sobre la base de V1 para no hacerlo, es no obstante una razón para no hacer A?" (por ejemplo, “¿Cuando tenemos una razón para no ser gentiles -esto es, cuando tenemos una razón para no hacer aquello que se funda en un valor que juzgamos normalmente digno de ser perseguido, precisamente porque se funda en ese valor-, el hecho de que hacer A sería gentil es una razón para hacerlo -aunque sea superada por una ulterior razón que se encuentra en conflicto con ella- o es ello mismo una razón para no hacerlo?") es artificial, y no es susceptible de una respuesta unívoca. Pero, una vez más, no es plausible que una alternativa teóricamente significativa dependa de cómo se responde a preguntas como ésta. 